\title{
Isolation and Identification of the Dominant Flora of the Intestinal Microbiota of Rattus norvegicus from an Algerian West Farm
}

\author{
Ould Yerou Karima ${ }^{1^{*}}$, Meddah $\mathrm{B}^{2}$ and Tir Touil $\mathrm{A}^{3}$ \\ ${ }^{1}$ Laboratory of Bioconversion, Microbiological Engineering and Health Security, Algeria \\ ${ }^{2}$ Laboratory for Research on Biological Systems and Geomatics, Algeria \\ ${ }^{3}$ Faculty of Science, Department of Biology, University of Mascara, Algeria
}

*Corresponding author: Ould Yerou Karima, Laboratory of Bioconversion, Microbiological Engineering and Health Security, Algeria, Tel: 213 663971364; E-mail: mhanine11@yahoo.fr

Received date: January 31, 2017; Accepted date: February 15, 2017; Published date: February 22, 2017

Copyright: ( 2017 Karima OY, et al. This is an open-access article distributed under the terms of the Creative Commons Attribution License, which permits unrestricted use, distribution, and reproduction in any medium, provided the original author and source are credited.

\begin{abstract}
The intestinal flora called the intestinal microbiota, consists of different bacteria and other microorganisms which occur naturally in the gastrointestinal tract organs components. These tract bacteria are present in their millions and help the functioning of the body in particular allowing aid to degradation of certain molecules into absorbable substrates. They also protect against invasion of the gut by other pathogenic bacteria, that is to say which may be responsible for disease. Factors like stress, antibiotics and diet can affect the balance of intestinal flora and in case of imbalance, digestive disorders type bloating, diarrhoea or vomiting may occur. Rattus norvegicus of weights 100 $\mathrm{kg}$, from Algerian West Firm are scarified and isolation of their ileum and colon respectively. Two strains of bacteria, Escherichia coli and Lactobacillus are then purified and identified.
\end{abstract}

Keywords: Intestinal flora; Rattus norvegicus, Escherichia coli; Lactobacillus; Algerian West Farm

\section{Introduction}

The intestine is an eco-physiologique continuously changing, houses a microbial population present steadily, abundant, diversified, complex named: intestinal microbiota [1].

The digestive tract of man and animals is an enclave in the external environment that hosts a bacterial population characterized by its density and its complexity. It has the state of balance, that is to say in the adult weaned, the microbial flora of the distal portions of the digestive tube reached between $5 \times 10^{10}$ and $2 \times 10^{11}$ viable cells per gram fresh content; more than 190 species have been isolated from the human flora [2].

\section{Material and Methods}

\section{Animal Material}

The laboratory rat (Rattus norvegicus) is only an albino form of Norway rat. The black rats albinos are more rare in the laboratories, because more difficult to breed in captivity. The ease of the Norway rat to reproduce is an essential factor in its success in the laboratory. It's small size limit in addition the surface of its habitat and therefore the constraints of its livestock.

After breeding, mating, gestation and put down to levels of the farm of our university (Mascara, Algeria), we chose of rats of the male sex weighing approximately $100 \mathrm{~kg}$, not having health problems (chronic rat, immune system Low, trend pushed to the abscesses, tumor, diabetes, etc.) or presenting a physical malformation.

\section{Dissection, sacrifice and collection of intestine}

\section{Material and reagents for dissection}

Materials: Petri Boxes, Bunsen burner, Gloves, Masks, Cotton, Jarre desiccator, Plateau at dissection, Dissecting kit (pins at dissection, splined probe, Clamp, Grapple to Ends dishes, strong scissors, scalpels).

Reagents: Physiological water, Chloroform, Alcohol.

\section{Method of dissection}

1) After preparing the necessary hardware previously sterilized and saw the pain that will be imposed on the animal during manipulation, for this and according to the Protocol and the nature of the rats, it is recommended to practice the sacrifice and the dissection on the animal under anesthesia at the vapor of chloroform in a desiccator for a few minutes in the best hygienic condition.

2) Meadows of the Bunsen burner, the rat is extended on the ventral surface and pin on a plank sterile. It performs a simple laparotomy.

3) It draws the digestive system as follows:

(i) It raises toward the front the lobes of the liver which overlie the stomach. This last to one aspect of a large pocket, whitish and curved.

(ii) It draws the spleen.

(iii) It ligation and removes the digestive tube by putting it in a box of sterile kneaded containing the sterile physiological saline to eliminate any trace of blood

(iv) It cut with care the mesenteries in which circulate a rich vascular network to unroll the intestine that extends from the stomach to the cecum of the large intestine; 
Citation: Karima OY, Meddah B, Tir TA (2017) Isolation and Identification of the Dominant Flora of the Intestinal Microbiota of Rattus norvegicus from an Algerian West Farm. J Antimicrob Agents 3: 135. doi:10.4172/2472-1212.1000135

Page 2 of 6

(v) It splits the small and large intestine and taking only the ileum that leads in the large intestine by the intermediary of the valve ileocecal and the settler who appears as a succession of blisters and the rectum which leads to the anus.

\section{Isolation and identification of bacteria required}

\section{Material and reagents}

Materials : Pasteur pipettes, Petri boxes, test tubes, rack to tubes, Bunsen burner, blades, beak of coloring, spray, Graduated pipette, vortex, micropipette, tips, syringes, aluminum foil, gloves, masks, grapple, parafilms, candle, Jarre desiccator, agitator, Barrou magnetic, beakers, flasks, sterile, Bell of Durham, balance, autoclave, $\mathrm{pH}$ meter, microscope, incubator, bain marie, refrigerator.

Reagents: physiological water, distilled water, violet of gentian, fushine Lugol,, alcohol, malachite green to $5 \%$, safranin to $5 \%$, xylene, oil of emersion, distilled water sterile, $\mathrm{NaOH}, \mathrm{HCl}$, Kovacs, VP1, VP2, NIT1, NIT2, $\mathrm{H}_{2} \mathrm{O}_{2}$, disks of the Oxidase ONPG discs, the Vaseline oil, bleach.

\section{The bacterial strains isolated}

a) Escherichia coli, isolated from colon;

b) Lactobacillus, isolated from the ileum.

\section{The culture media}

A. Selective media of isolation: coli;

i) Mid EMB (eosin methylene blue) and Hectoen for Escherichia

ii) Mid SRM (of Man, Rogosa and Sharpe) Agar for Lactobacillus.

B. Backgrounds to Biochemical identification: API 20E, Simmons citrate, Clark and lubs, mannitol mobility. TSI (Triple Sugar Iron), Möeller broth with arginine and MRS broth.

C. Middle of conservation: Nutrient Agar tilted and MRS tilted.

D. Environments of resuscitation: MRS broth for Lactobacillus and Nutrient broth (BN) for E. coli.

\section{Method for the isolation and identification}

\section{Isolation of bacterial strains}

The insulation is a technique that allows you to separate the bacteria of a sample; the insulation allows to obtain different settlements, spaced apart from each other. It seeks to isolate the different cells of the sample, each isolated cell then being likely to lead to a colony [3].

\section{Seeding in the culture media}

A $0.1 \mathrm{ml}$ dilution of $10^{-6}$ is spread on various agars cooled in a petri dish of environments SS and Hectoen, the boxes are incubated at $37^{\circ} \mathrm{C}$ aerobically for 24 (Figure 1).

\section{a) Insulation of Lactobacillus}

Lactobacilli are present in rich media containing carbohydrate substrates of the intestinal mucosa. It is more suited to survive in the distal part of the small intestine (ileum). The insulation is difficult and uses a particular environment the mid SRM in anaerobic conditions. This is in effect of bacteria which have need of very many factors of growth (auxotrophy).

\section{Preparation of the solution mother and the dilutions}
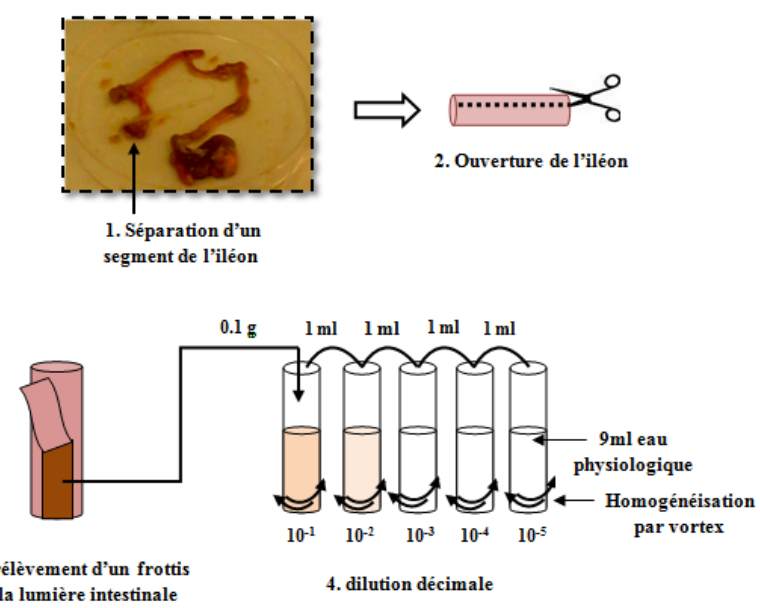

Figure 1: Preparation of the mother solution and the dilutions to the ilium.

\section{Planting on the culture medium}

A $0.1 \mathrm{ml}$ of the dilution $10^{-5}$ is spread on various agars cooled in a petri dish of mid SRM, The boxes are incubated at $37^{\circ} \mathrm{C}$ anaerobically under atmosphere to $\mathrm{CO}_{2}$ during 48 hour.

\section{b) Isolation of Escherichia coli:}

Also called Escherichia coli is a bacterium very intestinal common among the Homo sapiens and comprised approximately $80 \%$ of the intestinal aerobic flora. It is without doubt the living organism the most studied to this day.

\section{Planting on the culture medium}

A $0.1 \mathrm{ml}$ of the Dilution $10^{-7}$ (Figure 2) is spread on various agars cooled in a petri dish of environments EMB and Hectoen, the boxes are incubated at $37^{\circ} \mathrm{C}$ aerobically for 24 hour.

\section{Purification of strains}

The purification is to take a single colony and to grow on the same medium of departure in several operations up to the obtaining of a pure strain. This allows you to avoid the possibility that viable organisms but inhibited, from the selective agars, contaminate the culture in the additional events. After 24 hour of incubation, the cultures are purified. The latter which allows to obtain pure cultures from strains obtained. The selection is based on the macroscopic aspect of the Colonies: the color, shape, diameter, the Opacity etc (Figures 3 and 4). A sample of each colony type (isolate alleged) is taken then purified by successive sub-culturing according to the method of scoring. [4]. 
Citation: Karima OY, Meddah B, Tir TA (2017) Isolation and Identification of the Dominant Flora of the Intestinal Microbiota of Rattus norvegicus from an Algerian West Farm. J Antimicrob Agents 3: 135. doi:10.4172/2472-1212.1000135

Page 3 of 6

\section{Identification of purified strains}

The identification of the isolates is based on their morphological characteristics, physiological and biochemical.

\section{Preparation of the solution mother and the dilutions}

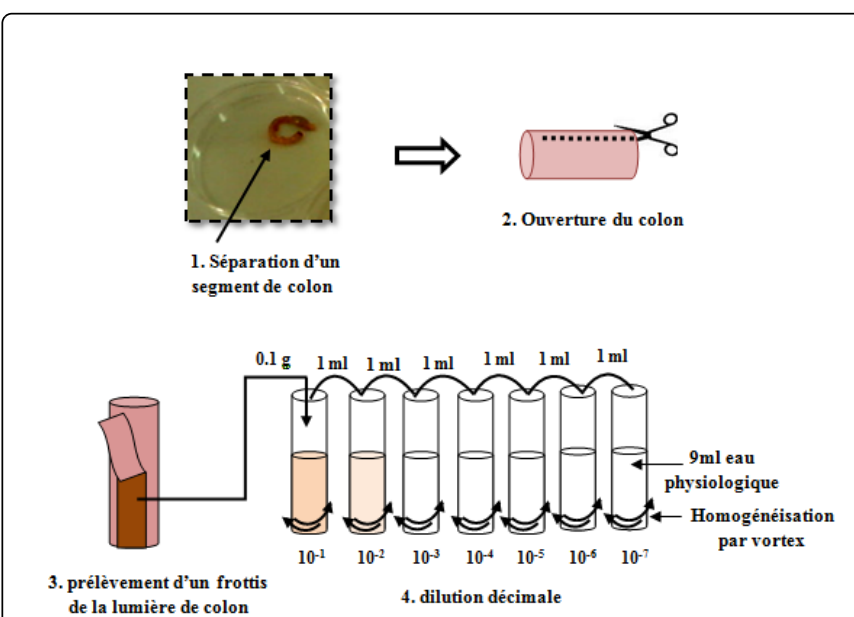

Figure 2: Preparation of the mother solution and the dilutions from the colon.

\section{Identification of $E$. coli}

Study of the morphological characters: This study is based on macroscopic and microscopic observations to differentiate the type of Gram, the hulls, bacteria as well as the disposition of the cells.

\section{Macroscopic examination}

The observation of the macroscopic aspect of the Colonies allows you to perform a first characterization, with a possible orientation of the results during the course of the identification. According to the authors [5], the elements of identification are macroscopic: the form of the settlements, the size of colonies by the measurement of the diameter, the chromogenic, elevation, the opacity and the surface.
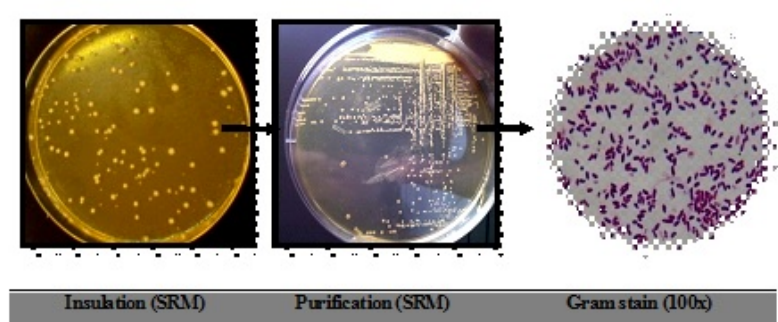

Purification(SKM)

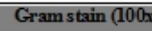

Figure 3: Appearance macroscopic and microscopic of S1.

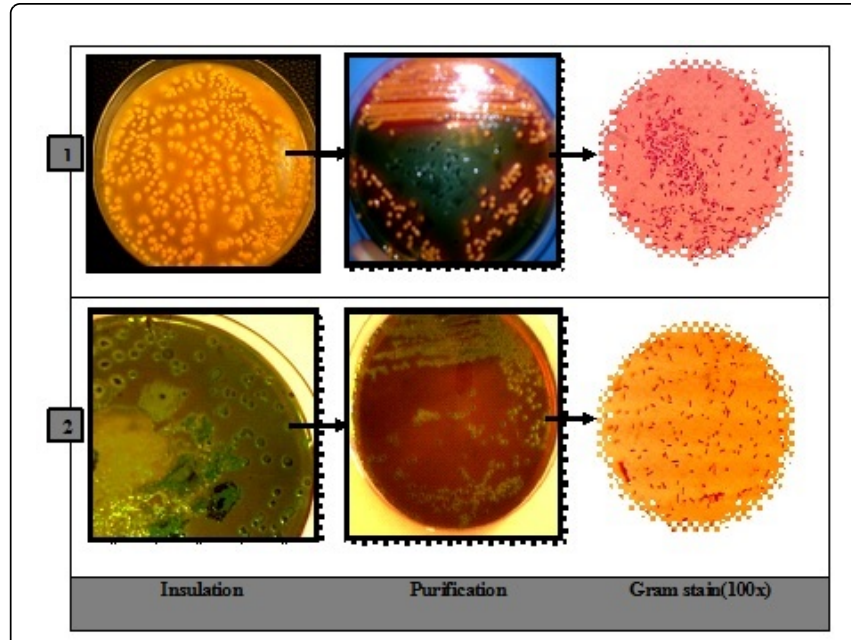

Figure 4: Appearance macroscopic and microscopic of S2 (1) Macroscopic appearance on Hectoen. (2) Macroscopic appearance on EMB.

\section{Observation to the state fees}

This test is used to determine the form, arrangement, and the mobility of bacteria. It consists in the observation of a drop of bacterial suspension, prepared with water physiological and placed between blade and blade. The observation is done on light microscope.

\section{Operating mode}

i) Remove a drop of a culture in liquid medium on a glass slide.

ii) Cover the drop of a lamella covers object

iii) Cover the blade with the molten wax

iv) Immediately observe under the microscope

v) After observation immediately throw away the blade in a reservoir containing the bleach.

Observation to the microscope: It is done in white light, direct lighting of the preparation (magnification: objective 40X).

\section{Complex coloration: Gram stain}

It is a double staining which allows us to know the shape, the arrangement, the purity as well as the biochemical nature of the cell wall purified. This coloration allows you to classify bacteria according to their ability to attach the crystal violet.

Those who possess an external envelope are discolored when washing to ethanol (Gram-), while those who do not possess will retain the dye (Gram+).

The consistency and the value of the Gram stain corresponds to biochemical differences between the wall of bacteria Gram-positive and $\mathrm{Gram}^{-}$negative bacteria [6].

\section{Technical}

i) Prepare and attach smear blight in the heat of the Bunsen burner. 
ii) Cover at the gentian violet for $1 \mathrm{~min}$;

iii) Add of Lugol's: Two baths of 45 seconds, discard the excess by the running water;

iv) Deal with the alcohol $95^{\circ} \mathrm{C}$ for 30 seconds, and then rinse with water;

v) Repaint the Fuschine during 1 to 2 minutes, rinse with water and then drying.

Observation to the microscope: It is done by adding the immersion oil. Gram-positive bacteria stain purple while the Gram-negative bacteria stain pink.

\section{Study of respiratory enzymes: Terminal}

\section{Search for the oxidase}

Principle: This test allows the detection of the phenylene-diamine oxidase or cytochrome oxidase; incoming enzyme in various pairs of redox. Acting on a colorless substrate, cetenzyme leads to the formation of a semi-quinone red. This lasts to very unstable, if oxyderapidement to give a blackish compound [6].

\section{The technique}

i) On a filter paper sterile, remove a disk of the oxidase impregnated with dimethyl-para-phenylenediamine;

ii) Moisten the disc with a few drops of sterile distilled water. An excess of water can hurt reading;

iii) Using a Pasteur sterile pipette take the bacterium to identify (culture of 18-24 hours) and the deposersur the disk.

Reading: Emergence of a violet coloration immediately: the strain is called positive oxidase.

\section{Research of the catalase}

Principle: Catalase is an enzyme having the property to decompose the hydrogen peroxide $\left(\mathrm{H}_{2} \mathrm{O}_{2}\right)$ with release of oxygen according to the following reaction [6].

$$
2 \mathrm{H}_{2} \mathrm{O}_{2}----->2 \mathrm{H}_{2} \mathrm{O}+\mathrm{O}_{2}
$$

Technique: On a blade and using a Pasteur pipette, we remove a bacterial colony to which is added the oxygenated water (10 Volumes).

Reading: Catalase ${ }^{+}$: Effervescence/catalase ${ }^{-}$: Not of effervescence.

\section{A. Study of biochemical characters}

The gallery API 20E: This test band API-20E (bioMerieux Inc.) which is used to identify Gram-negative bacilli has enteric 20 compartments of dehydrated test separated. A bacterial suspension is used to rehydrate each of the wells.

Some of the wells will have of color changes resulting from differences in $\mathrm{pH}$. Other produce sub-products which should be identified with the reagents.

A number of profile is determined according to the series of tests + and -, which allows to identify the species.

\section{Method}

\section{Prepare a suspension of the bacteria}

Inoculate a large colony (diameter of 2-3 $\mathrm{mm}$ ) of the bacterium in a solution of $0.85 \% \mathrm{NaCl}$.

\section{Inoculate the band API}

i) Taking into the tape to a slight angle with the top of the table, now inoculate the bacterial suspension in each of the wells with a Pasteur pipette sterile;

ii) Oucher the end of the pipette on the side of the Cup allowing the fluid to penetrate in the wells by the capillary action while applying slight pressure on the bulb. This should prevent the formation of bubbles in the wells. Each well must be filled up to the neck;

iii) Fill the tube and the section of the Cup of the tubes [CIT], [VP] and [Freeze];

iv) Following inoculation, completely fill the section of the capitulum of $\mathrm{ADH}$ microtubes, LDC, ODC, $\mathrm{H}_{2} \mathrm{~S}$ and ERUS with mineral oil.

\section{Incubate the band in its room}

i) Fill the bottom of the house with just enough water to fill the indents;

ii) Place the band in this tank from the bottom;

iii) Place the top of the chamber incubation on the bottom and labelled there;

iv) Place the band at $37^{\circ} \mathrm{C}$.

\section{Interpretation}

i) Add the appropriate reagents to the compartments: 1 drop of reagent of Kovac to the IND, 1 drop of reagent of Barritt A and B to the VP, 1 drop of $\mathrm{FeCl}_{3}$ to the TDA;

ii) Make the reading of all other tests, such as in the table, without the addition of reagents;

iii) Note the results and compare the positive reactions with the table of differentiation.

\section{B) Identification of the alleged strains of Lactobacillus}

A) Study of the morphological characters:

1) Macroscopic examination

2) Microscopic aspect

3) Observation to the State fees

4) Complex coloration (Gram)

B) Identification physiological and biochemical effects

1) Research of the catalase

2) Study of the fermentative type: It require a pure culture and young of the lactic strains in a tube containing the broth of SRM and the bell of Durham to highlight the production of gas and thus determine the fermentative type of our strains to know homofermentaire (not for the production of gas) and 
Page 5 of 6

heterofermentaire (production of gas). Incubation is done at $37^{\circ} \mathrm{C}$ for 24 hours to 7 days. After the incubation the presence or the absence of the gas in the bell indicates the fermentative type [6]

3) Growth temperature: It has been tested by seeding a culture Young of 24 hour in the boil on adequate. The tubes were incubated for seven to ten days to 10 and $15^{\circ} \mathrm{C}$ and for $24 / 48$ hours at 45 and $50^{\circ} \mathrm{C}([6-8])$.

4) Growth at different $\mathrm{pH}$ : The medium used is MRS broth adjusted to different $\mathrm{pH}(3.3 / 4.8 / 9.6)$, incubation $37^{\circ} \mathrm{C} / 48$ hour [6].

5) Heat-resistant: It require a pure culture and young of the lactic strains in a tube containing the broth of SRM, incubation at $63.5^{\circ} \mathrm{C}$ for 30 min [9].

6) Hydrolysis of the esculin: The hydrolysis of this heteroside is highlighted on the agar medium to the esculin, inoculate the mid BEA from a culture of $24 \mathrm{~h}$ and incubate at $30^{\circ} \mathrm{C}$ during 24 hour to 48 hours. A positive reaction is reflected by a blackening of the middle due to the ferric salts soluble and esculetin. For the negative bacteria, the Middle remains unchanged but there is growth. [10].

7) Hydrolysis of the arginine: Planting into a tube of Moeller broth with arginine and a control tube (Moeller broth without arginine), the two tubes are covered with 4 to $5 \mathrm{~mm}$ of sterile paraffin oil. Incubation is done at $30^{\circ} \mathrm{C}$ for at least 4 days. The culture in the middle of basis is manifested by a turn to yellow due to the metabolism of glucose. The strains which have the ADH (arginine dihydrolase) will acidify the middle by fermenting glucose (turn to yellow). This acidification promotes the activity of the arginine dihydrolase which will degrade the arginine and release the ammonia. It leads to an alkalization environment which is manifested by a shift of the $\mathrm{pH}$ indicator to purple.

Production of acetoin: The search for the acetoin is tested by the reaction of vogues proskauer (VP), after a culture of 24 hour at $30^{\circ} \mathrm{C}$ on mid Clark and Lubs. Add 5 drops of Reagent VP1 (soda solution $\mathrm{NaOH}$ at $16 \%$ in distilled water) and the same volume of the Reagent VP2 (alpha-naphthol to $6 \%$ in the alcohol at $95^{\circ} \mathrm{C}$ ). Carefully shake the tubes and wait for a maximum time of $10 \mathrm{~min}$. The presence of acetoin translates into a pink coloration on the surface but that can disseminate in the whole Middle [10].

Use of citrate: Some bacteria have the ability to use citrate as the sole source of carbon and energy. To detect this particularity, it uses the mid Simmons citrate; a SLOPED AGAR which will be seeded in the streaks on the slope. After incubation, the bacterium is called citrate ${ }^{+}$, when the $\mathrm{pH}$ indicator turns toward the blue (alkalization of the middle) [11].

Use of IST sugars (Triple sugar iron): This medium (IST) not only allows implementing the fermentation of three sugars: glucose, sucrose and lactose in the absence or in the presence of $\mathrm{O}_{2}$, but also to detect the production of $\mathrm{H}_{2} \mathrm{~S}$. To determine therefore these characters, the MID is seeded in gall by central bite and the slope by striate.

The fermentation of sugars is reflected by the acidification of the Environment (glucose on the gall, sucrose and lactose on the slope). The production of the gas is determined by its presence in the nerve, whereas the formation of $\mathrm{H}_{2} \mathrm{~S}$ is reflected by a blackening of middle or only at the level of the planting [12].

Use of the mannitol: Mannitol is the product of reduction of the mannose, the degradation of this polyol led to the formation of a chain of acids which explains the turning of the indicator phenol red to yellow including the planting is carried out by a central bite. The low quantity of agar contained in the middle (semi-solid) allows mobile bacteria to disseminate to colonize all the tube, whereas those immobile will grow along the bite only [8].

Search for $\beta$-galactosidase: Test of Ortho-NitroPhenylGalactopyranoside: The $\beta$-galactosidase is responsible of the fractionation of the lactose present in the environment in two molecules: glucose and galactose, but which requires the presence of another enzyme $ß$-galactoside permease.

It is indeed able to hydrolyze any similar molecule of lactose, which explains the use of the ONPG in the laboratory. The technique is realized in preparing a suspension loaded in micro-organism, which we introduced a disk impregnated with ONPG. After an incubation of 30 minutes to $37^{\circ} \mathrm{C}$, the turn of the mixture to yellow reveals the presence of the enzyme [5].

\section{Conservation of strains}

The isolated strains of E. coli and Salmonella are retained in test tubes containing a mid GN tilted. The strains are seeded on the slope of the tubes by the method of scoring, and then incubated at $37^{\circ} \mathrm{C}$ for 24 hours. The tubes in which there has been a growth will be kept at $4^{\circ} \mathrm{C}$ for duration of 4 to 6 weeks. In order to be able to always have viable strains, the reactivation must be done all months [11]. The strains of Lactobacillus are seeded on agar SRM tilted in tube. After incubation at $30^{\circ} \mathrm{C}$ for 24 hours, the tubes are kept at $+4^{\circ} \mathrm{C}$. The subcultures are every three or four weeks [9].

\section{Results and Discussion}

\section{Study of the morphological characters of the bacterial isolates}

\begin{tabular}{|c|c|c|c|}
\hline $\begin{array}{l}\text { Bacterial } \\
\text { isolate }\end{array}$ & Mid & $\begin{array}{l}\text { Macroscopic } \\
\text { appearance }\end{array}$ & Microscopic aspect \\
\hline S1 & Srm & $\begin{array}{l}\text { Small white colony, } \\
\text { creamy, smooth, convex. }\end{array}$ & $\begin{array}{l}\text { Gram+, not spore, non- } \\
\text { mobile, long stick and } \\
\text { end. }\end{array}$ \\
\hline \multirow[t]{2}{*}{ S2 } & $\begin{array}{l}\text { Hecto } \\
\text { en }\end{array}$ & $\begin{array}{l}\text { Diameter: } 1 \mathrm{~mm} \text { to } 2 \mathrm{~mm} \text {, } \\
\text { salmon, smooth, convex, } \\
\text { creamy. }\end{array}$ & $\begin{array}{l}\text { Gram -, coccobacille, } \\
\text { mobile, isolated or } \\
\text { grouped by pairs. }\end{array}$ \\
\hline & EMB & $\begin{array}{l}\text { Diameter: } 1 \text { to } 3 \mathrm{~mm} \text {, dark } \\
\text { purple with a greenish } \\
\text { metallic sheen, flat, } \\
\text { viscous. }\end{array}$ & $\begin{array}{l}\text { Gram -, coccobacille, } \\
\text { mobile, isolated or } \\
\text { grouped by pairs. }\end{array}$ \\
\hline
\end{tabular}

Table 1: The aspect macroscopic and microscopic of bacterial isolates.

\section{Identification of physiological and biochemical effects of bacterial isolates}

\begin{tabular}{|l|l|}
\hline Physiological and Biochemical characteristics & Result \\
\hline Catalase & - \\
\hline Fermentative type & Homofermentaire (gas-) \\
\hline Growth temperature & $10^{\circ} \mathrm{C}, 45^{\circ} \mathrm{C}$ \\
\hline
\end{tabular}


Citation: Karima OY, Meddah B, Tir TA (2017) Isolation and Identification of the Dominant Flora of the Intestinal Microbiota of Rattus norvegicus from an Algerian West Farm. J Antimicrob Agents 3: 135. doi:10.4172/2472-1212.1000135

Page 6 of 6

\begin{tabular}{|l|l|}
\hline Heat-resistant to $63.5^{\circ} \mathrm{C}$ & + \\
\hline Growth $\mathrm{pH}$ & 9.6 \\
\hline Hydrolysis of the arginine & + \\
\hline Production of acetoin & - \\
\hline Glucose use & + \\
\hline Use lactose & + \\
\hline Use sucrose & + \\
\hline Use of the mannitol & + \\
\hline Use of citrate & - \\
\hline Beta galactosidase & + \\
\hline Hydrolysis of the esculin & + \\
\hline
\end{tabular}

Table 2: Identification physiological and biochemical effects of bacterial isolate $\mathrm{S} 1$.

After the study of morphological and biochemical strain S1 isolated on the mid SRM (Tables 1 and 2) and according to the identification key for [6], it is found that it is of genus Lactobacillus sp.

\section{Biochemical identification of S2 and S3}

\begin{tabular}{|l|l|}
\hline Biochemical character & S2 \\
\hline Beta galactosidase & + \\
\hline Arginine dihydrolase & - \\
\hline Lysine decarboxylase & + \\
\hline Ornithine decarboxylase & + \\
\hline Use of citrate & - \\
\hline Production of $\mathrm{H}_{2} \mathrm{~S}$ & - \\
\hline Urease & - \\
\hline Tryptophan deaminase & 1 \\
\hline Production of indole & + \\
\hline Production of acetoin & - \\
\hline Gelatinase & - \\
\hline Use of Glucose & + \\
\hline Use of mannitol & + \\
\hline Use of inositol & + \\
\hline Use of Sorbitol & + \\
\hline Use of rhamnose & + \\
\hline Use of sucrose & + \\
\hline Use of melibiose & + \\
\hline
\end{tabular}

\begin{tabular}{|l|l|}
\hline Use of amygdalin & - \\
\hline Use of arabinose & + \\
\hline Nitrate reductase & + \\
\hline Oxidase & - \\
\hline Catalase & + \\
\hline$+:$ positive; - : Negative; / : Not of reagent &
\end{tabular}

Table 3: Biochemical identification of bacterial isolates S2.

The reading of the gallery must be done by referring to the Table 3 to read the API 20E. Then, the bacterial isolates presumed to S2 are Escherichia coli.

\section{Conclusion}

The intestine is an essential organ in which the transformation and the absorption of food. It also has a role of barrier of protection vis-a-vis bacteria of viruses and many toxic products. It was targeted our study on two commensal bacteria isolated from the intestinal microbiota of laboratory rats "Rattusnorvegicus": Escherichia coli and Lactobacillus $s p$. by methods simple but modern molecular biology applied to these living organisms enabled the identified.

\section{References}

1. Abdlert I, Carlsson B, Deman P (1991) Tract Colonization With Enterobacteriaceae in Pakistani and Swedish hospital -delivered infants. Acta paediatrica 8: 602-611.

2. Frenci $\mathrm{T}$ (2001) Hungry bacteria definition and properties of a nutritional state. Environ Microbiol 3: 605-611.

3. Berg RD (1983) Translocation of indigenous bacteria from the intestinal tract in intestinal human micro flora in health and disease. DJ Academic Press, New York pp: 333-351.

4. Amrouche (2005) Contribution to the study of power immunomodulator of bifidobacteries. Thesis presented to the Faculty of Graduate Studies of the University of Laval in the framework of the program of Doctorate in Sciences and Technology of Foods for the degree of Philosophiae doctor (PHD).

5. Hang HC, Bertozzi QC (2005) Gastrointestinal mucus. Org Bio Med Chem 13: 5021-5034.

6. Deer (1991) Micoecologie tract. Encycle Med Chir: 1-8.

7. Begley M, Gahan CGM, Hill C (2005) The interaction between bacteria and bile. FEMS Micobio Rev 29: 625-651.

8. Ganong W, Jpbin M (2005) Medical Physiology (2nd edn.) Boeck University p: 477.

9. Chancheyras F-Durand, Fontty G (2007) The digestive ecosystems. International Medical Lavoisier pp: 255-261.

10. Dore J, Rigottier-Gois (2004) The studies methods :intestinal microbial flora, physiological and physiology and digestive pathology. ED Biocodex, Paris.

11. Handle F (2008) Collective. Dorland medical dictionary bilingual.

12. Prescott H, Klein KN (2003) The normal microflora and the resistance not specific to the microbiology host (2edn) De Boeck University pp: 699-673. 